\title{
IN SILICO STUDY OF NEW STRUCTURAL ALERTS OF AGENTS CLASTOGENIC
}

Guardado Yordi, E.; ${ }^{1,2}$ Matos, M.J.; ${ }^{2}$ Uriarte, E.; ${ }^{2}$ Pérez Martínez, A.;1,3 Santana, L.; ${ }^{2}$

Molina, E. ${ }^{1,2}$

${ }^{1}$ Universidad de Camagüey Ignacio Agramonte Loynaz, Cuba; ${ }^{2}$ Universidad de Santiago de Compostela, España; ${ }^{3}$ Universidad Estatal Amazónica, Ecuador.

\section{SUMMARY}

Natural polyphenols and their derivatives from diet have been reported by their pro-oxidant and clastogenic activities. In an aim of elucidating structural alerts for this genotoxicity endpoint, a QSTR study was conducted under the TOPS-MODE approach. It was possible to establish structural alerts from the DNA oxidative damage as an endpoint of clastogenicity at optimum leaders with high probability of being clastogenic. Some important fragments to obviate this activity were also identified. The results constitute a reference system for designing new food or pharmaceutical matrices as an alternative to the experimental toxicology.

KEYWORDS: structural alerts; pro-oxidant activity; clastogenicity; flavonoids; TOPSMODE approach. 


\section{INTRODUCTION}

Combinatorial chemistry applied to computational toxicology allows to explore a broad universe of molecular structures from materials that nature has selected on the basis of evolution. In this context, the use of computational approaches (in silico) allow a thorough exploration of the structural diversity that can be created from structural patterns (1). Estrada et al. (2004) raised the possibility of combining approaches QSAR (Quantitative StructureActivity Relationship) and generating structures as a way for the discovery of new chemical entities of interest (2). In this project, it is shown how the use of the approach TOPS-MODE (Topological Sub-Structural Molecular Design) and substructural analysis lead to the identification of critical structural alerts for clastogenic activity of a series of compounds derived from the basic skeleton of flavonoids, and maximum alerts clastogenicity.

\section{METHODS}

Dataset was created including polyphenolic compounds with reported pro-oxidant activity and a series of design derivatives. It was taken into account the decodification of the clastogenic structure-activity relationship for the selection of the structural alerts of maximal clastogenicity described by Yordi et al. (2012). The alerts correspond to previous QSAR studies, centred in flavonoids reported as pro-oxidants in vitro, presented in food plants(3). The selected precursors present and hydrocarbonated scaffold: C6-C3-C6. They are flavonoids from the subclasses: flavonols, flavanones and isoflavones. In figure 1 it is shown the prediction using TOPS-MODE approach and applied methodology. 


\section{QSTR STUDY}

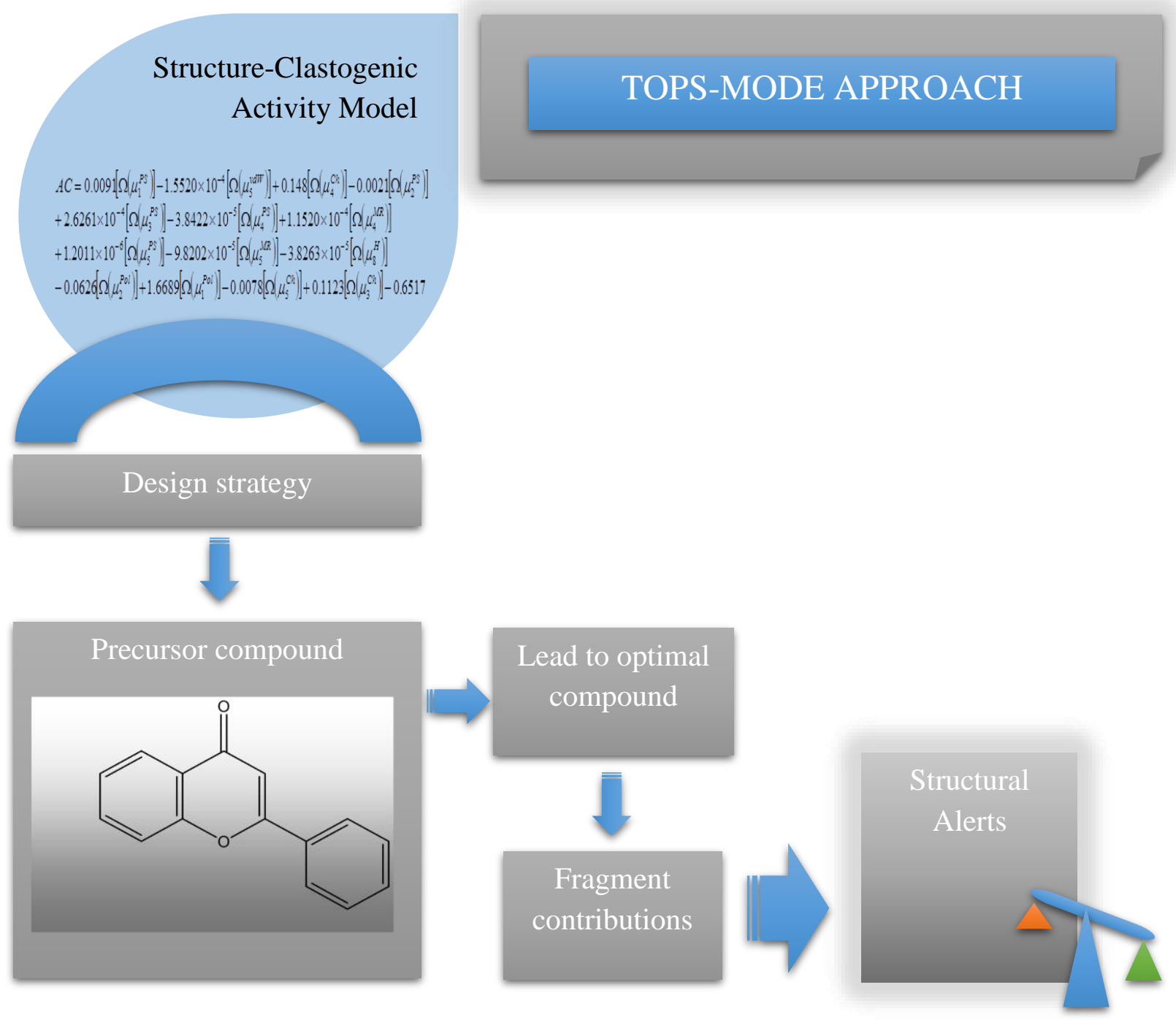

Fig. 1. Scheme of the applied methodology.

\section{RESULTS AND DISCUSSION}

In Figure 2 are represented the chemical criteria used for the design of lead and optimal compounds. The design strategy was based on: i) generate transformations into precursors centred in the molecular formation, until the inclusion of a furan ring; ii) submit the lead compounds to a methylation process. In Table 1 it is shown the dataset and structure 
compounds used. The prediction and fragment contributions are represented in the table 2 and figure 3 , respectively.

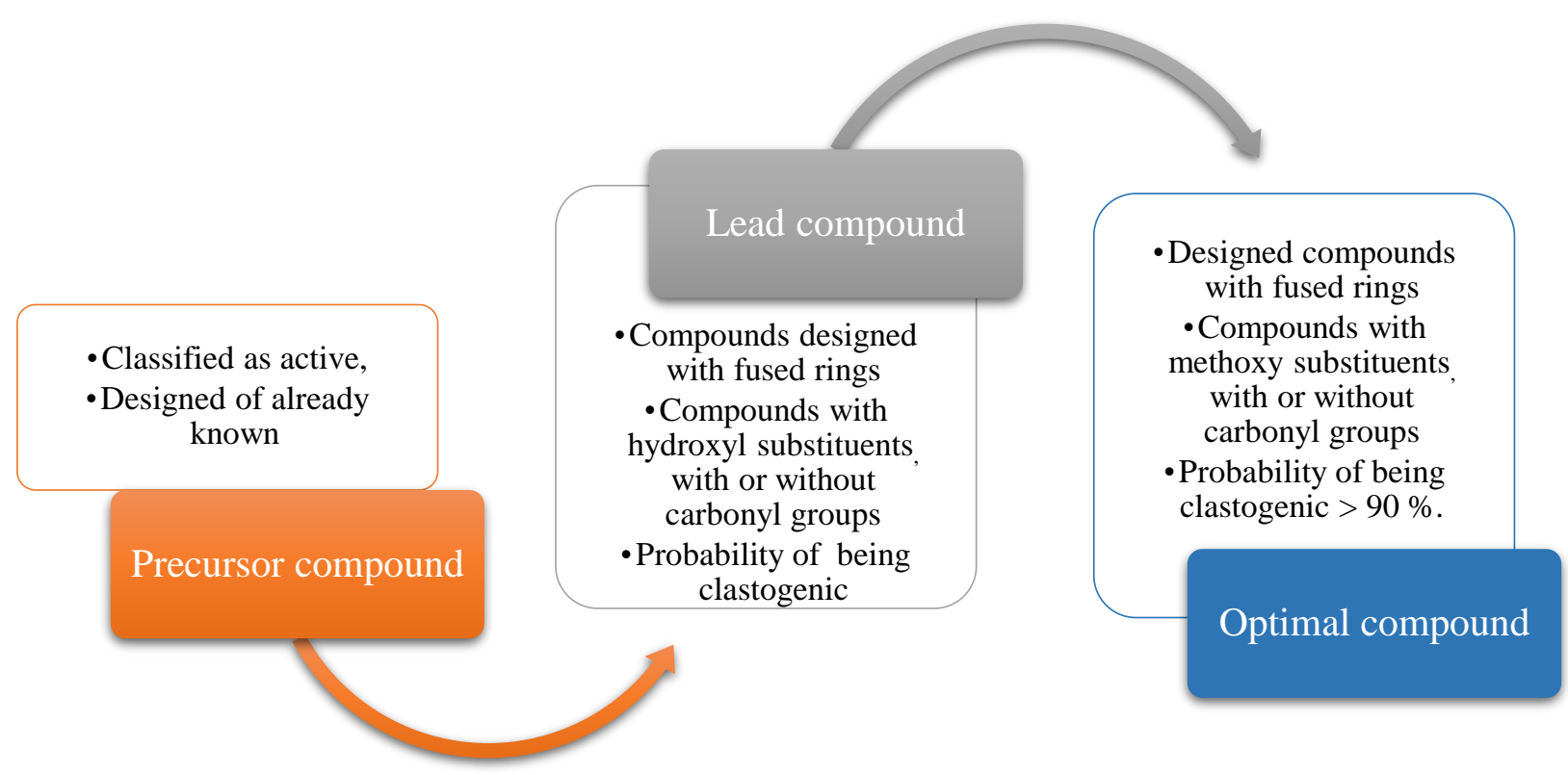

Fig. 2. Selection criteria and characteristics of which level of designed compound (precursor compound, lead compound or optimal compound).

Table 1. Structure of the compounds present in the dataset.

\begin{tabular}{|c|c|c|c|c|c|c|c|c|c|}
\hline $\begin{array}{l}\text { Design } \\
\text { Group }\end{array}$ & Subclass & Precursor & 3 & 5 & 7 & $2^{\prime}$ & $\mathbf{3}^{\prime}$ & $4^{\prime}$ & $6^{\prime}$ \\
\hline \multirow{2}{*}{$\mathbf{I}$} & Flavonol & Designed (FOL 3)* & $\mathrm{OH}$ & $\mathrm{OH}$ & $\mathrm{OH}$ & $\mathrm{OH}$ & $\mathrm{H}$ & $\mathrm{OH}$ & $\mathrm{OH}$ \\
\hline & Flavanon & Designed (FAN 3)* & $\mathrm{OH} \mathrm{H}$ & $\mathrm{OH}$ & $\mathrm{OH}$ & $\mathrm{OH}$ & $\mathrm{H}$ & $\mathrm{OH}$ & $\mathrm{OH}$ \\
\hline \multirow{2}{*}{ II } & \multirow{2}{*}{ Flavonol } & Datiscetin** & $\mathrm{OH}$ & $\mathrm{OH}$ & $\mathrm{OH}$ & $\mathrm{OH}$ & $\mathrm{H}$ & $\mathrm{H}$ & $\mathrm{H}$ \\
\hline & & Morin** & $\mathrm{OH}$ & $\mathrm{OH}$ & $\mathrm{OH}$ & $\mathrm{OH}$ & $\mathrm{H}$ & $\mathrm{OH}$ & $\mathrm{H}$ \\
\hline III & Isoflavone & Designed (iFON 5) & $\mathrm{OH}$ & $\mathrm{OH}$ & $\mathrm{OH}$ & $\mathrm{OH}$ & $\mathrm{H}$ & $\mathrm{OH}$ & $\mathrm{OH}$ \\
\hline IV & Flavanon & Designed (FAN 6)* & $\mathrm{OH} \mathrm{H}$ & $\mathrm{OH}$ & $\mathrm{OH}$ & $\mathrm{OH}$ & $\mathrm{OH}$ & $\mathrm{OH}$ & $\mathrm{H}$ \\
\hline
\end{tabular}


Table 2. In silico clastogenic activity prediction of the design compounds.

\begin{tabular}{|c|c|c|c|c|c|}
\hline Precursor & $\%$ Prob $^{a}$ & Lead & $\%$ Prob & Methoxyl lead & $\%$ Prob \\
\hline FOL 3 & 77.8 & FOL Lead & 86.0 & FOL Lead Me* & 99.9 \\
\hline FAN 3 & 80.4 & FAN Lead & 92.3 & FAN Lead Me* & 99.9 \\
\hline Datiscetin & 56.1 & FOL Lead 2 & 68.8 & FOL Lead $2 \mathrm{Me}$ & 96.0 \\
\hline Morin & 66.5 & FOL Lead 3 & 77.5 & FOL Lead $3 \mathrm{Me}^{*}$ & 99.2 \\
\hline iFON 5 & 75.0 & iFON Lead & 78.7 & iFON Lead Me* & 99.8 \\
\hline FAN 6 & 83.7 & FAN Lead 2 & 93.6 & FAN Lead $2 \mathrm{Me}^{*}$ & 99.9 \\
\hline
\end{tabular}

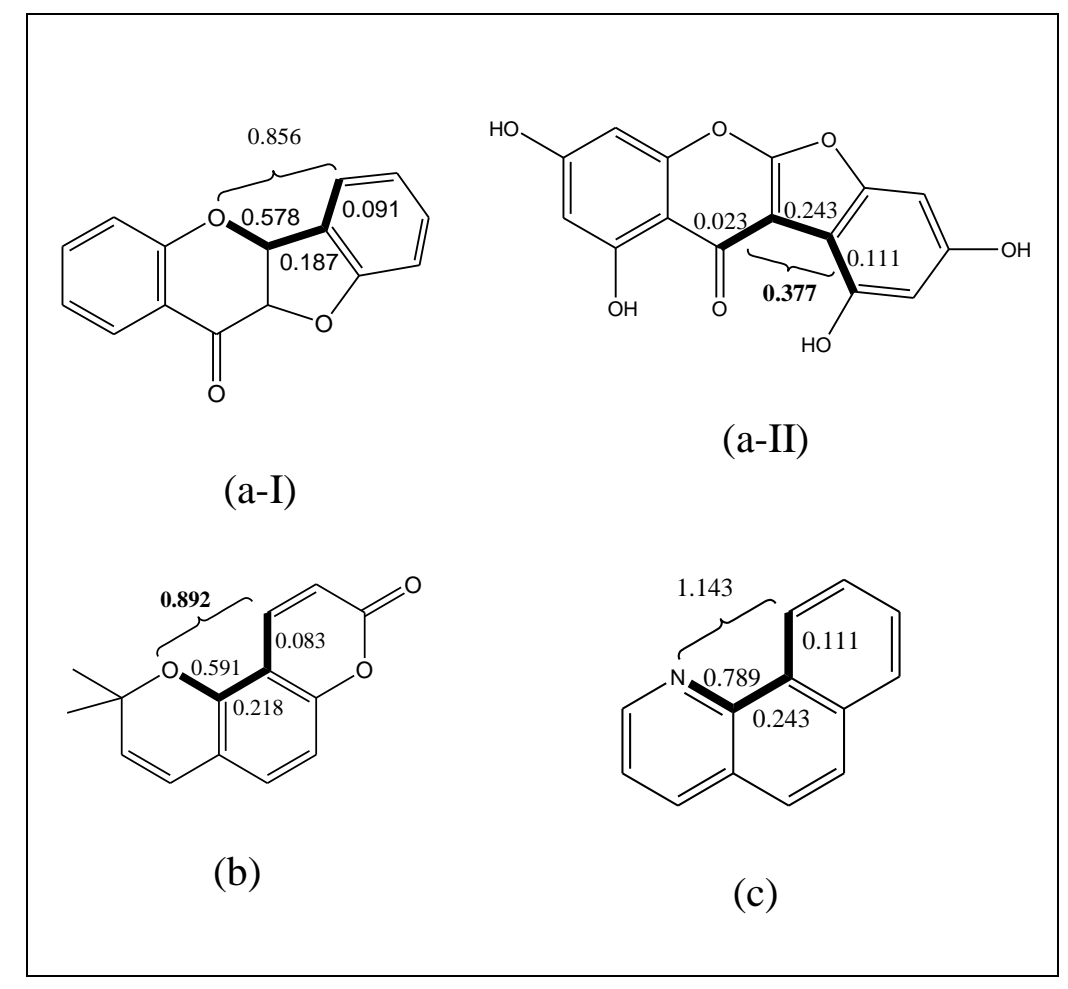

Fig. 3. Example fragment positive contributions of bay region of (A) tetracyclic fused ring system designed, a-I (0.856), a-II (0.377) compared as (B) Benzo(h)quinoline (BHQ) (0.892), Saeki et al. (2003) Estrada et al. (2006) and (C) Pyranocoumarins (angular type) (1.143) (4). 


\section{CONCLUSIONS}

The phenybenzolpyran skeleton of flavonoids has been a precursor of a series of structural alerts for maximum clastogenicity. This toxicological alert could be of interest in making decisions involving an assessment of the risk/benefit of molecular entities. An in silico design strategy is based on structural alerts to the clastogenicity that may have reported pro-oxidant molecules presented in this article. Transformation of hydroxyl to methoxy groups in the same positions, are an active element of great importance. This should be in conjunction with the formation of a fourth ring that provides the formation of a bay region, area of influence to the activity. This topological-statistical model can be used in predicting clastogenic and non-clastogenic substances, and the design can be used to characterize new chemical entities. This theoretical study also allows the identification of local fragments that contribute to the activity. Methoxy groups proved to be the functional elements that mostly influence the achievement of the optimal results. It can also be a benchmark of importance in the design of compounds targeting functional foods or dietary supplements.

\section{ACKNOWLEDGMENTS}

The authors thank the partial financial support of University of Santiago de Compostela, University of Camagüey Ignacio Agramonte Loynaz, Galician Plan of research, innovation and growth 2011-2015 (Plan I2C) and E1031P01 Programa de Doutoramento en Ciencia e Tecnoloxía Química.

\section{REFERENCES}

1. De Julian-Ortiz JV. Virtual Darwinian Drug Design: QSAR, inverse problem, virtual combinatorial chemistry and computational screening. Comb Chem High Throughput Screen. 2001;4 (3):295-310.

2. Estrada E, Quincoces JA, Patlewicz G. Creating molecular diversity from antioxidants in Brazilian propolis. Combination of TOPS-MODE QSAR and virtual structure generation. Mol Divers. 2004;8:21-33. 
3. Yordi EG, Molina E, Matos MJ, Uriarte E. Structural alerts for predicting clastogenic activity of pro-oxidant flavonoid compounds: quantitative structure-activity relationship study. J Biomol Screen. 2012;17 (2):216-24.

4. Yordi EG, Matos MJ, Santana L, Uriarte E, Abreu O, Molina E. Natural coumarins: QSTR approaches regarding their genotoxicity. Biological and Chemical Research. 2015; Volume 2015:241-57. 